\title{
Use of genitalia preparations in the species determination of Leafminers (Agromyzidae: Diptera)
}

\author{
Ram Bahadur Thapa \\ Department of Zoology \\ Post Graduate Campus, Tribhuvan University, Biratnagar, Nepal \\ E-mail:niwaj@yahoo.com
}

\begin{abstract}
Morphological characters are not sufficient in the species determination of leaf miners. Preparing genitalia slides, making illustrations and their studies were used in the present investigation. 15 species of flies were redescribed and 13 more species were described and named as new, associated with leguminous host. Many species of leaf miners were also reared on various non-leguminous hosts from eastern Nepal. About 1500 genitalia slides were prepared for this work. Interspecific and intraspecific variations were illustrated. More variations were found in the interspecific group. Small variation was found in causing speciation.
\end{abstract}

Key words: Leaf miners, Diptera, Agromyzidae, redescription

\section{Introduction}

Male genitalia slides are prepared in the determination of species of leaf miners (Agromyzidae, Diptera). Leaf miners are minute flies measuring few millimeters. Their immature stage can damage agricultural crops and other plants. They make mines on leaves, stems, roots, pods and seeds, inflicting economic losses.

Classical taxonomy, chemotaxonomy and other morphological characters are not sufficient in species determination. Investigators follow newer trends in taxonomy.

\section{Materials and Methods}

The present study was carried out at Govind Ballabh Pant University of Agriculture and Technology, Pantnagar (Naintal) and Department of Zoology, Post-Graduate Campus, Tribhuvan University, Biratnagar, Nepal.

Male flies were reared from various infected plants. Alive puparia of flies were collected and incubated. The male flies recovered were pinned and preserved. The abdomen of relaxed flies was pinched off and transferred to a test tube containing $15 \% \mathrm{KOH}$. Later the abdomens were washed and dehydrated. The processed abdomens of flies were stored separately in clove oil. Genitalia slides were made by dissecting abdomen, illustrated and studied. In addition of redescription of many species of flies, 13 new species were also described and named. New names were proposed to the new species of leaf miners (Thapa, 2013).

Description of the flies were also made. Characters were put in keys. First times description along with genitalia illustration was used in keys. Identification of a species based on genitalia illustration was made. Host plants and biology of leaf miners were also studied.

\section{Results and Discussion}

Thapa (1991) has described 28 species of agromyzid flies belonging to 7 genera. These have been identified on 34 different leguminous host plants from Pantnagar, U.P. India. In addition of 
redescribing 15 species 13 agromyzid flies has been described as new species and new names were proposed to them. Thapa (1997) did an investigation on taxonomic diversity, biology and host range of leaf miners in morang District, Eastern Nepal. Further Thapa (2000) reared and identified 13 species of agromyzid flies belonging to 5 genera from eastern Nepal. Poudyal (2003) working on cultivated leguminous crops in Jhapa district, eastern Nepal has reported 4 species of agromyzid flies. Thapa Moon (2005) studied field population and diversity of leaf miners infesting mung bean Vigna radiata (Linn.) Wilczek grown in Biratnagar, eastern Nepal. She recorded 6 species of flies.

Keys based on genitalia illustration were included from Thapa (1991,2013). Male genitalia were characterized by hypandrium being large and well developed. Pregonites and postgonites were normally well differentiated; former was sometimes to be fused with hypandrium. Epandrium was large and conspicuous with surstyli and cerci normally well developed with characteristic setae or setulae. The aedeagus complex: was characterized by having aedeagal apodeme large and darkly sclerotized. Aedeagal hood was conspicuous. Aedeagus was with distinct basal section and consisted of basiphallus and phallophore and distinct distal section. It was consisting of various sclerites forming mesophallus and distiphallus. The terminal section of ejaculatory duct inside distiphallus was normally well developed with apodeme. The apodeme was normally well developed, sometimes reduced with conspicuous bulb. Keys of leaf miners under studies were made with genitalia illustrations. All following illustrations were made by Thapa $(1991,2011,2012,2013)$.

Derivations of specific names of the new species proposed (Thapa, 1991)

1. Japanagromyza puerarivora new species ex leaves of Pueraria phaseoloides (Roxb.)

2. Melanagromyza pathaki new species ex stems of Cassia sp.

3. Melanagromyza glycini new species ex stems of Glycine max (Linn.) Merril.

4. Melanagromyza denticulata new species ex stems of Medicago denticulata willd.

5. Melanagromyza pisiphaga new species ex stems of Pisum sativum Linn.

6. Melanagromyza sehgali new species ex stems of Trifolium pratense Linn.

7. Melanagromyza vicivora new species ex stems of Vicia faba Linn.

8. Ophiomyia puerariae new species ex stems of Pueraria phaseoloides (Roxb.) Benth.

9. Ophiomyia sesbaniae new species ex stems of Sesbania aculeata Pers.

10. Ophiomyia mungivora new species ex stems of Vigna mungo Linn.

11. Ophiomyia spencera new species ex stems of Vigna mungo Linn.

12. Liriomyza fabae new species ex leaves of Vicia faba Linn.

13. Liriomyza pantnagarensis new species ex leaves of Vicia sativa Linn.

Name of species redescribed (Thapa, 1991)

1. Agromyza nana Meigen

2. Chromatomyia horticola (Goureau)

3. Japanagromyza tephrosiae (deMeijere)

4. Japanagromyza tristella (Thomson)

5. Liriomyza brassicae (Riley)

6. Liriomyza bryoniae (Kalt.)

7. Liriomyza strigata (Meigen)

8. Melanagromyza albisquama (Malloch)

9. Melanagromyza obtusa Malloch

10. Melanagromyza sojae (Zehntner)

11. Ophiomya alysicarpi (Bezzi)

12. Ophiomya centrosematis (deMeijere) 
13. Ophiomya cicerivora Spencer

14. Ophiomya phaseoli (Tryon)

15. Tropicomyia vigneae (Seguy)

Key to legume feeding species of the genus Japanagromyza Sasakawa from Northern India.

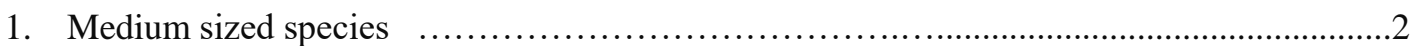

- Small sized species. Proposed name Japanagromyza puerarivora new species ex leaves of Pueraria phaseoloides (Roxb.) Benth. Aedeagus as in figure 1.

2. Orbit projected in front of eye margin in profile ........................................... indica Ipe.

- Orbit not projected in front of eye margin profile .................................................... 3

3. Wing length $1.89 \mathrm{~mm}$, ejaculatory apodeme quite long and narrow, aedeagus as in figure 2 , tephrosiae (de Meijere).

- Wing length $2.3 \mathrm{~mm}$, ejaculatory apodeme small and broad, aedeagus as in figure 3, tristella (Thomson).

Key to legume feeder species of the genus Melanagromyza Hendel from Northen India

1. Larger specimens, wing length 2.3-2.94 $\mathrm{mm}$ in males, pilose, reared from pods, aedeagus as in figures 4-6 obtusa (Malloch).

- Smaller specimens, wing length 1.68-2.1 mm in males, eyes bare, reared from pods or stems

2. Frons slightly broader than the width of eye, distiphallus with definite lateral lobes and spines but without terminal projections, aedeagus as shown in figures 7-13..sojae (Zehnter). - Frons relatively narrower; distiphallus with or without lateral lobes, terminal projections

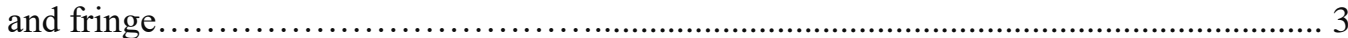

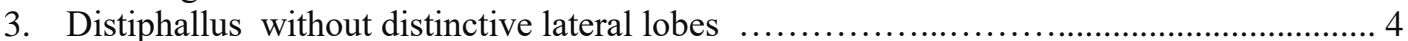

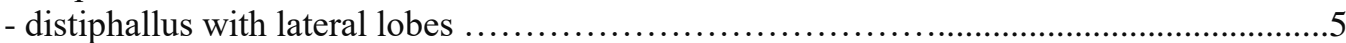

4. Reared from pods, distiphallus fringed and terminates into long projections, aedeagus as in figures 14-16........................................................................... albisquama (Malloch). - reared from stem, distiphallus devoid of fringes and terminal projections, but with a characteristic strong process. Proposed name Melanagromyza pathaki new species ex stems of Cassia sp., Aedeagus as in figure 17.

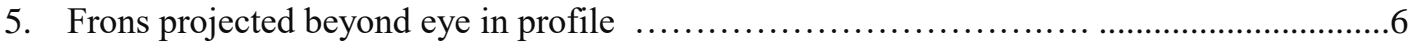

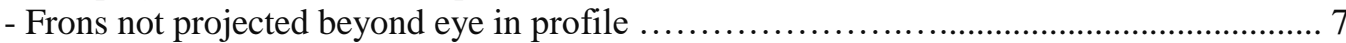

6. Third antennal article conspicuously elongate with an additional spine, spines strong; gena 1/6.66 vertical height of eye. Proposed name Melanagromyza glycini new species ex stems of Glycine max (Linn.) merril. Aedeaus as in figures 18-19.

- third antennal article round, spines inconspicuous, gena 1/4.2 vertical height of eye. Proposed name Melanagromyza vicivora new species ex stems of Vicia faba Linn. Aedeagus as in figure 20.

7. Orbits projected infront of eye margin in profile 8 - orbits not projected infront of eye margin in profile. Proposed name Melanagromyza sehagali new species ex stems of Trifolium pratense Linn. Aedeagus as in figure 21.

8. Orbits greatly enlarged and well projected infront of eye margin M .sp.n. ex stems of Medicago denticulata Willd. Proposed name Melanagromyza denticulata new species. Aedeagus as in figures 22-23.

- orbits normal and only slightly projected in front of eye margin. Proposed name Melanagromyza pisiphaga new species ex stems of Pisum sativum Linn. Aedeagus as in figures 24-25. 
Key to legume feeder species of Ophiomyia Braschnikov of Northen India

1. Males with vibrissal fasciculus, cicerivora Spencer, aedeagus as in figures 26-29.

- Males without vibrissal

2. reared from leaves, distiphallus sac like, alysicarpi (Bezzi). Aedeagus as in figures 30-31.

- reared from stems, and distiphallus not sac like

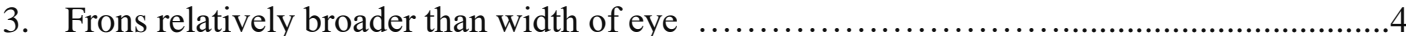

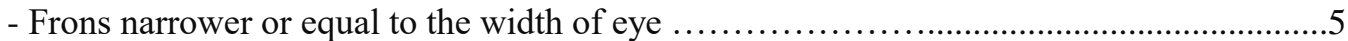

4. Frontal vitta, ocellar triangle both do not shine, aedeagus with highly asymmetrical basal sclerites, centrosematis (de Meijere). Aedagus as in figures 32-37.

- Ocellar triangle large, brilliantly shining black, Frontal vitta also brilliantly shining with reddish reflection, aedeagus without such highly asymmetrical basal sclerites, phaseoli (Tryon). Aedeagus as in figures 38-41.

5. Frons equal to the width of eye, $3^{\text {rd }}$ antennal article conspicuously elongated. Proposed name Ophiomyia mungivora new species, ex stems of Vigna mungo (Linn.) Heeper. Aedeagus as in figure 42.

- Frons relatively narrower, third antennal article round................................................ 6

6. Ocellar triangle large, characteristic aedeagus. Proposed name Ophiomyia spencera new species ex stems of Vigna mungo (Linn.) Heeper. Earlier, species name spencera was proposed as spenceri. As it is a case of junior homonomy, the spenceri has been rejected and replaced. Aedeagus as in figure 43.

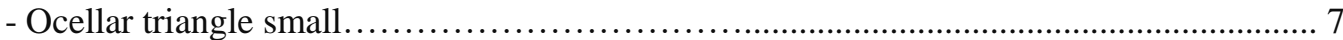

7. Ocellar triangle sunken, gena relatively broader, 1/5.3 vertical height of eye. Proposed name Ophiomyia sesbaniae new species, ex stems of Sesbania aculeata Pers. Aedeagus as in figure 44.

- Ocellar triangle not sunken, gena quite narrower, 1/10.5 vertical height of eye. Proposed name Ophiomyia puerariae new species, ex stems of Pueraria phaseoloides (Roxb.) Benth. Aedeagus as in figure 45.

Key to legume feeder species of the genus Liriomyza Mik from Northen India

1. Frons not projected beyond eye in profile.....strigata Meigen. Aedeagus as in figures 46-47.

- Frons projected beyond eye in profile

2

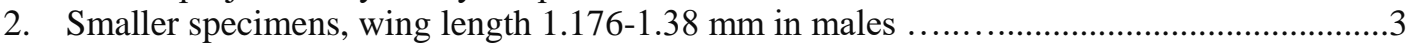

- Larger specimens, wing length $1.65-1.7 \mathrm{~mm}$ in males..............................................5

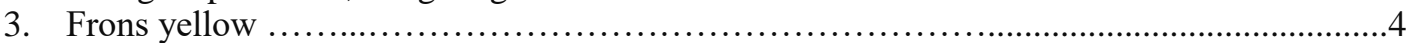

- Frons yellowish brown .............brassicae (Riley). Aedeagus as shown in figures 48-49.

4. Distal section of $\mathrm{M}_{3+4} 1.66$ times longer than basal portion.......... bryoniae (Kaltenbench). Aedeagus as shown in figures 50-51.

5. Distal section of $\mathrm{M}_{3+4}$ times longer than basal portion. Proposed name Liriomyza pantnagarensis, ex leaves of Vicia sativa Linn. Aedeagus as in figure 52.

6. Gena 1/3.2 vertical height of eye, lunule raised. Proposed name Liriomyza fabae new species, ex leaves of Vicia faba Linn. Aedeagus as in figures 53-54.

- gena $1 / 2$ the vertical height of eye, lunule sunken

tarai Garg.

Key to the legume feeder species of Tropicomyia and Chromatomyia

Small to minute black species. Larvae with serrated larval mouth hooks and make epidermal leaf mines. Pupation takes place in mine. Tropicomyia vignae (Seguy). Aedegus as in figures 55-60. -Medium size greyish species. Larvae pupate at the end of the mine with anterior pair of spiracles pierced through the leaf epidermis. Chromatomyia horticola (Goureau). Aedagus as in figures 61-63. 

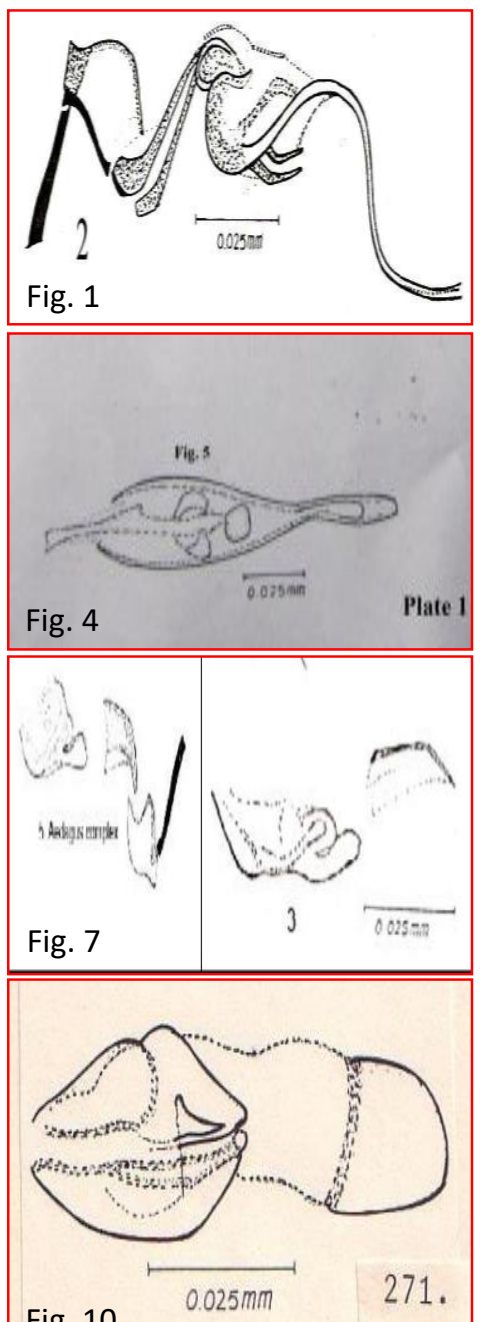

Fig. 10

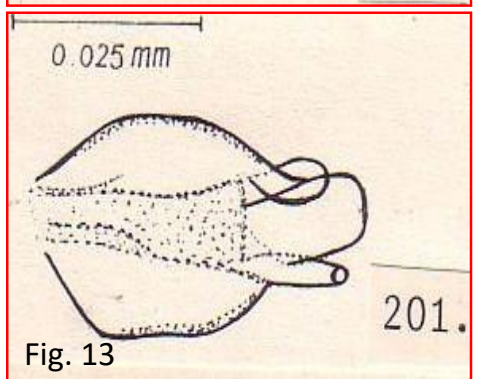

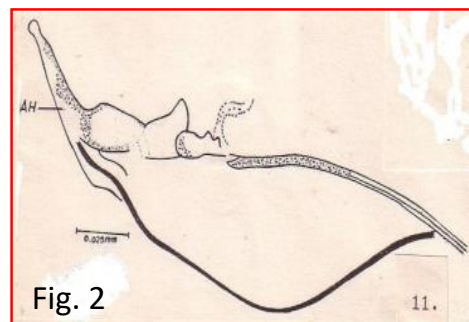

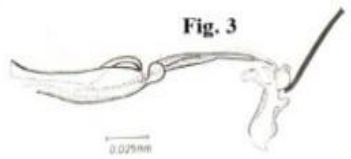

Fig. 5

Plate 3
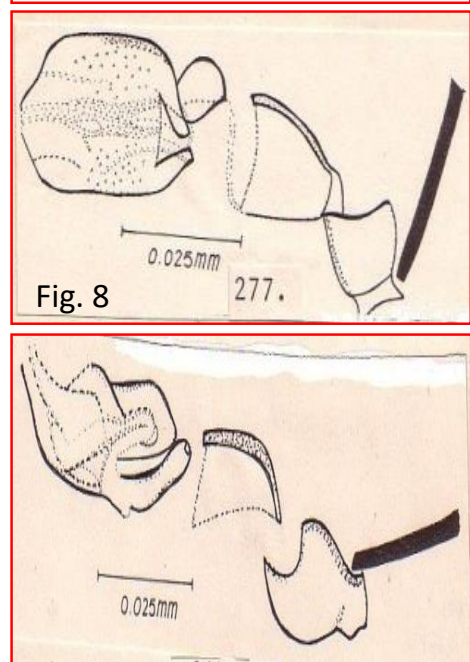

Fig. 11262.

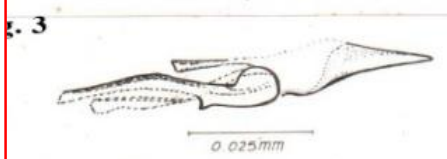

Plate 1

Fig. 14
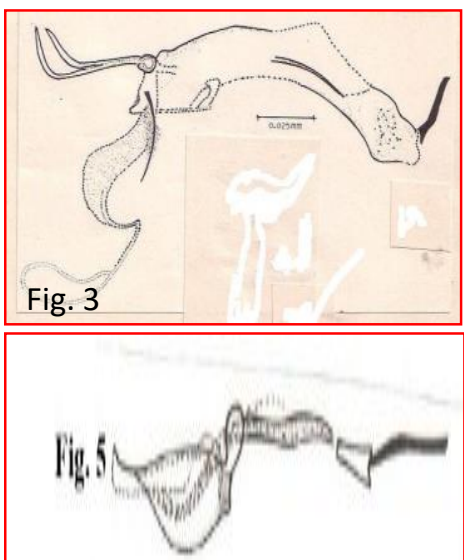

Fig. 6

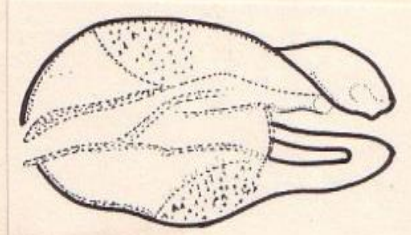

Fig. 9

$\overleftrightarrow{0.0063 \mathrm{~mm}}$
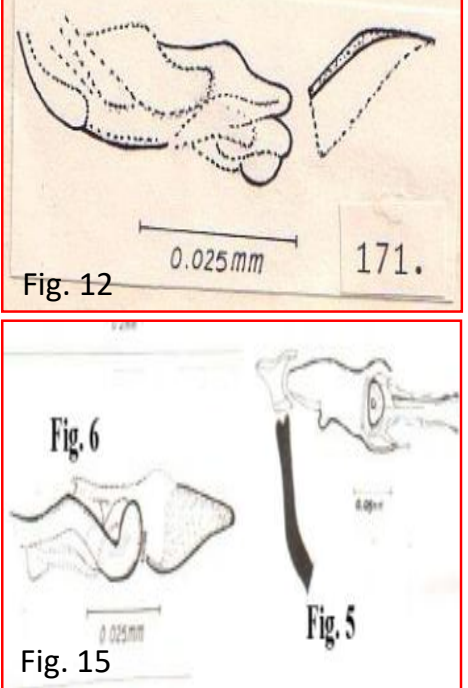

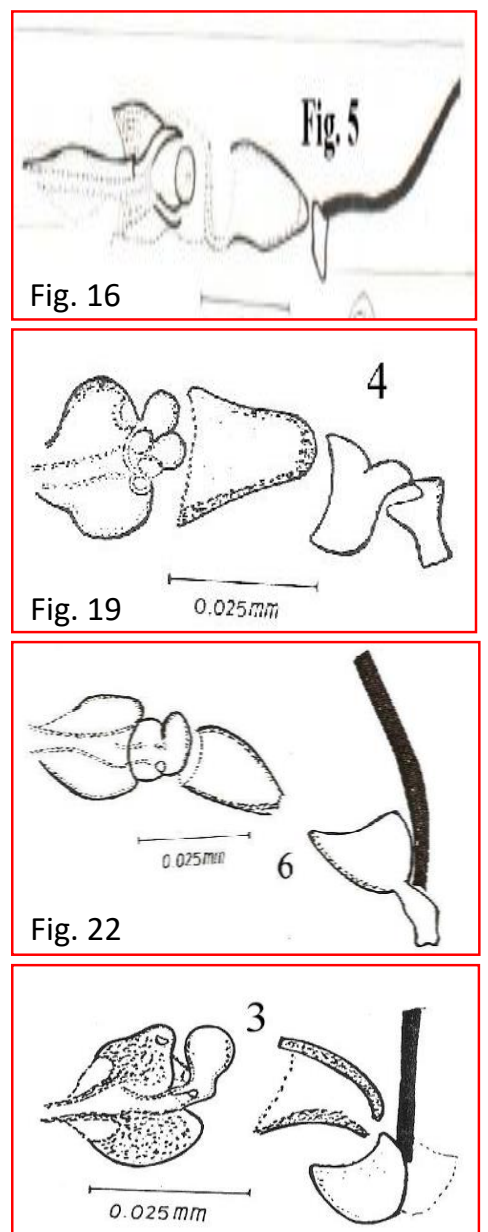

Fig. 25
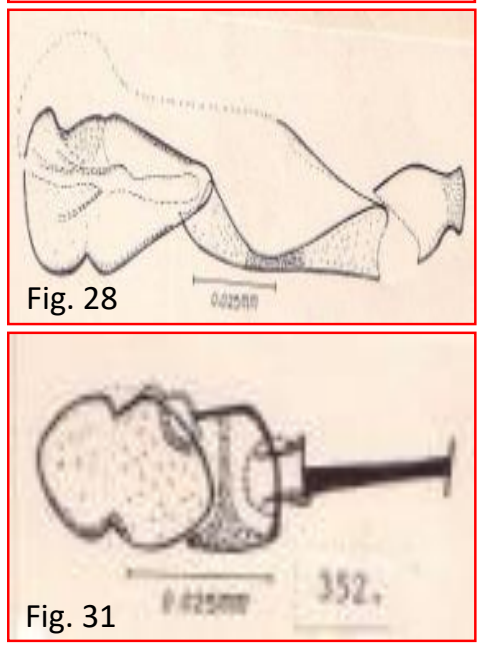
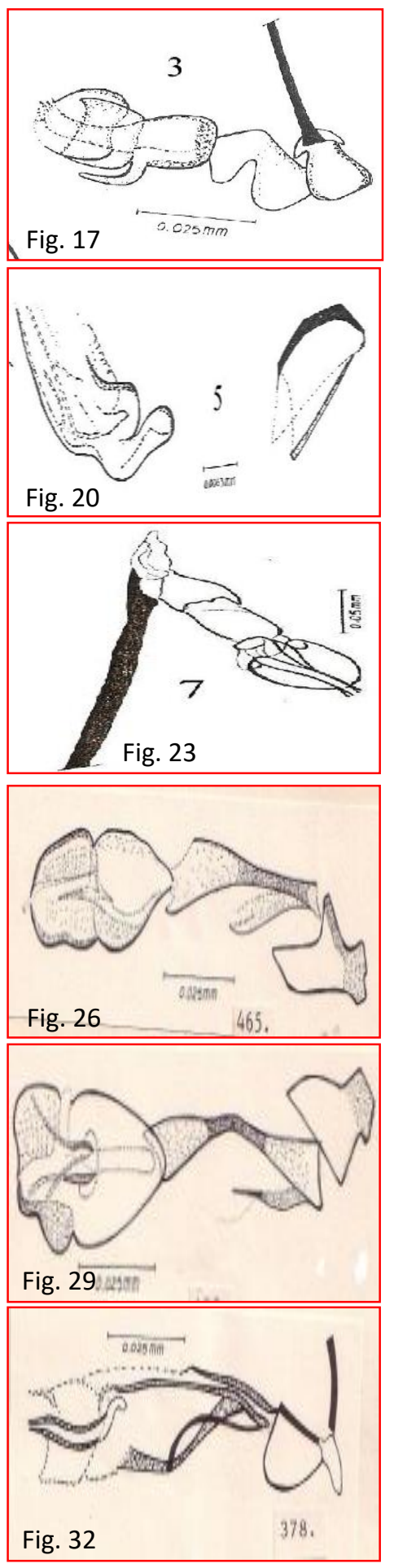
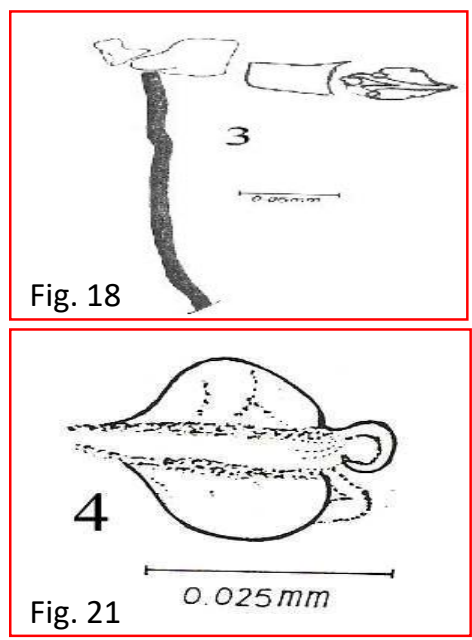

Fig. 21
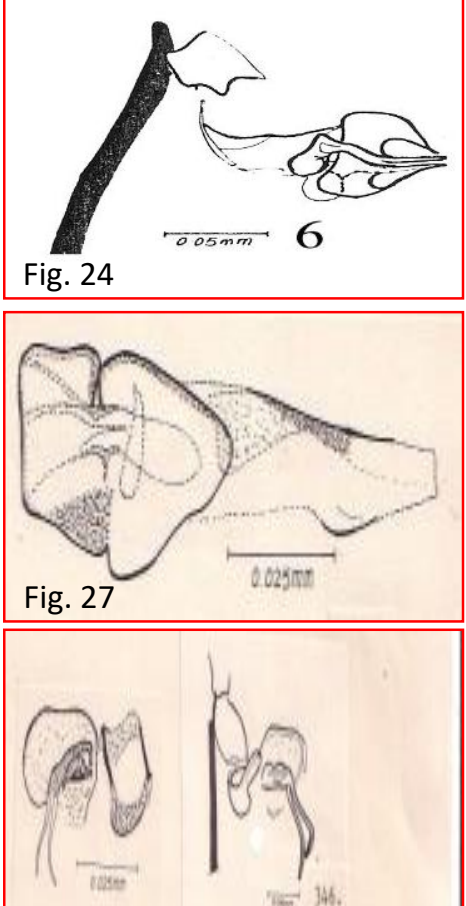

Fig. 30

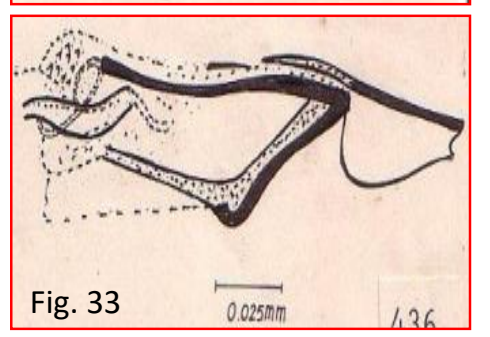



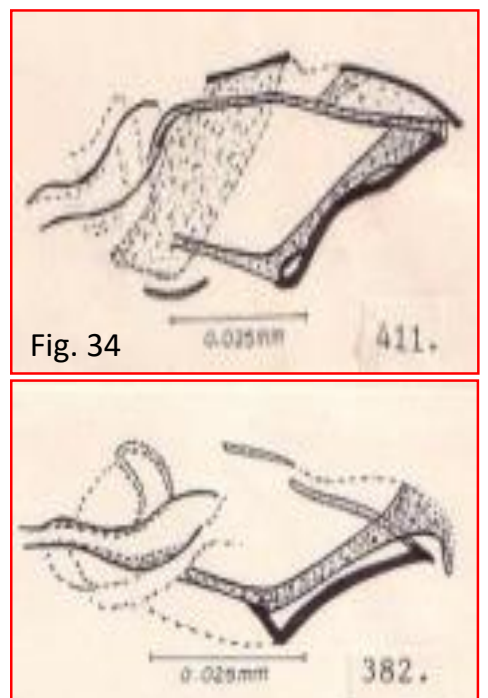

Fig. 37

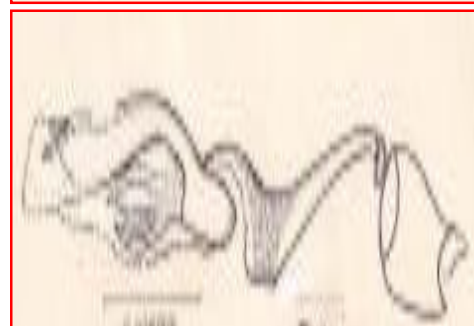

Fig. 40
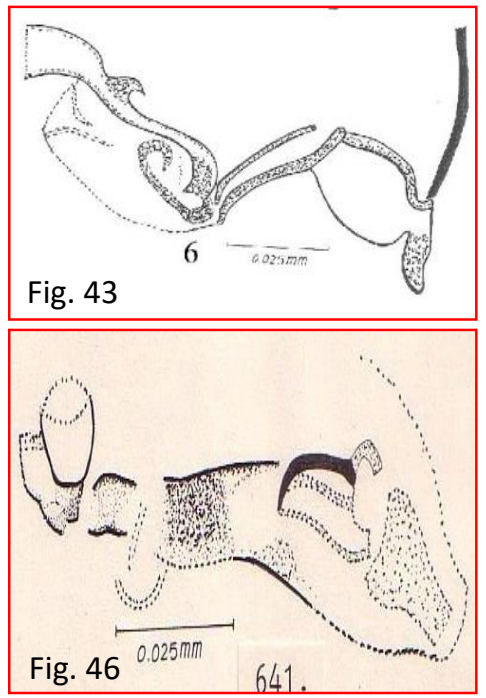
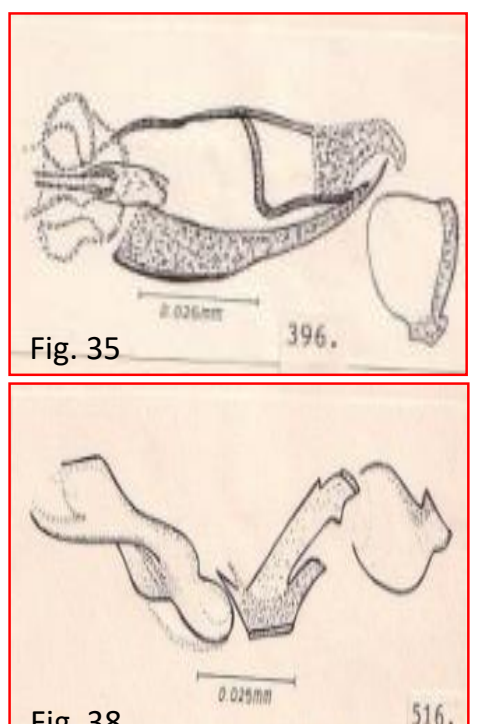

Fig. 38

516.

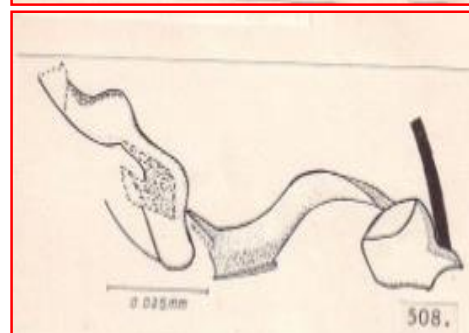

Fig. 41
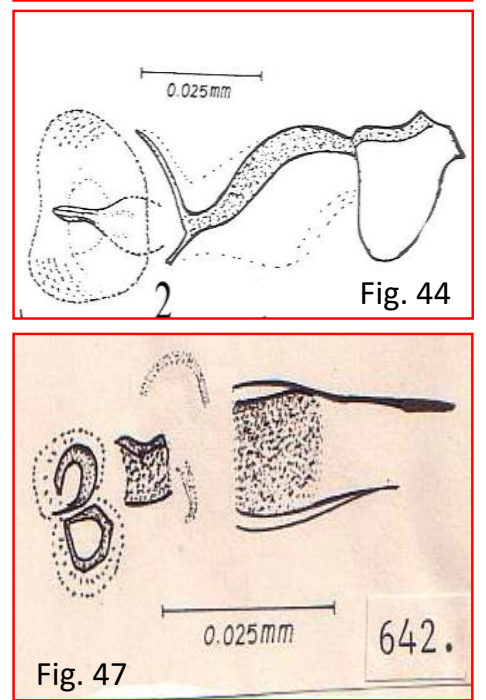
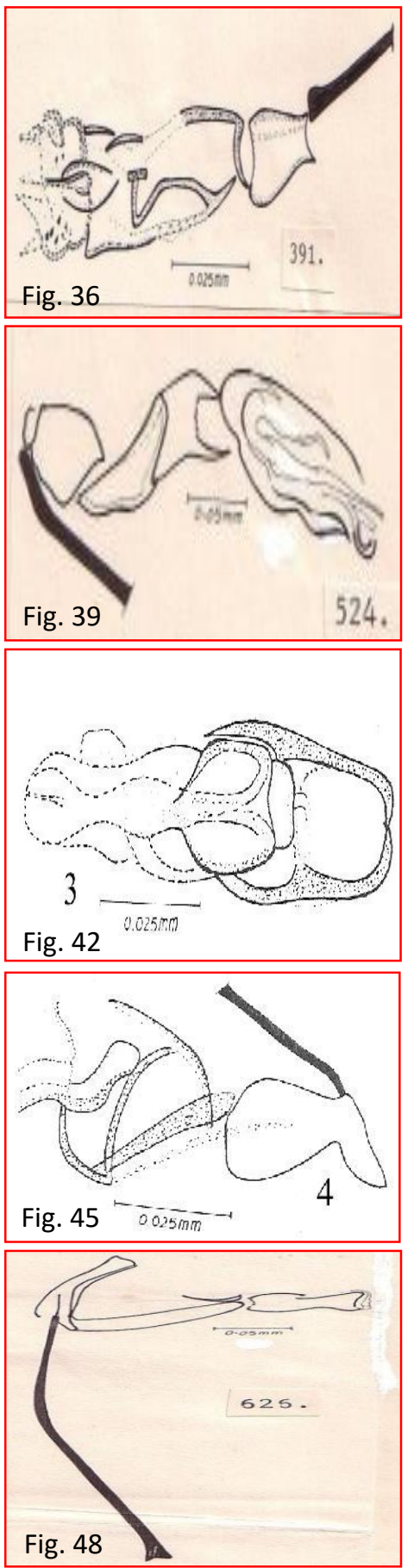

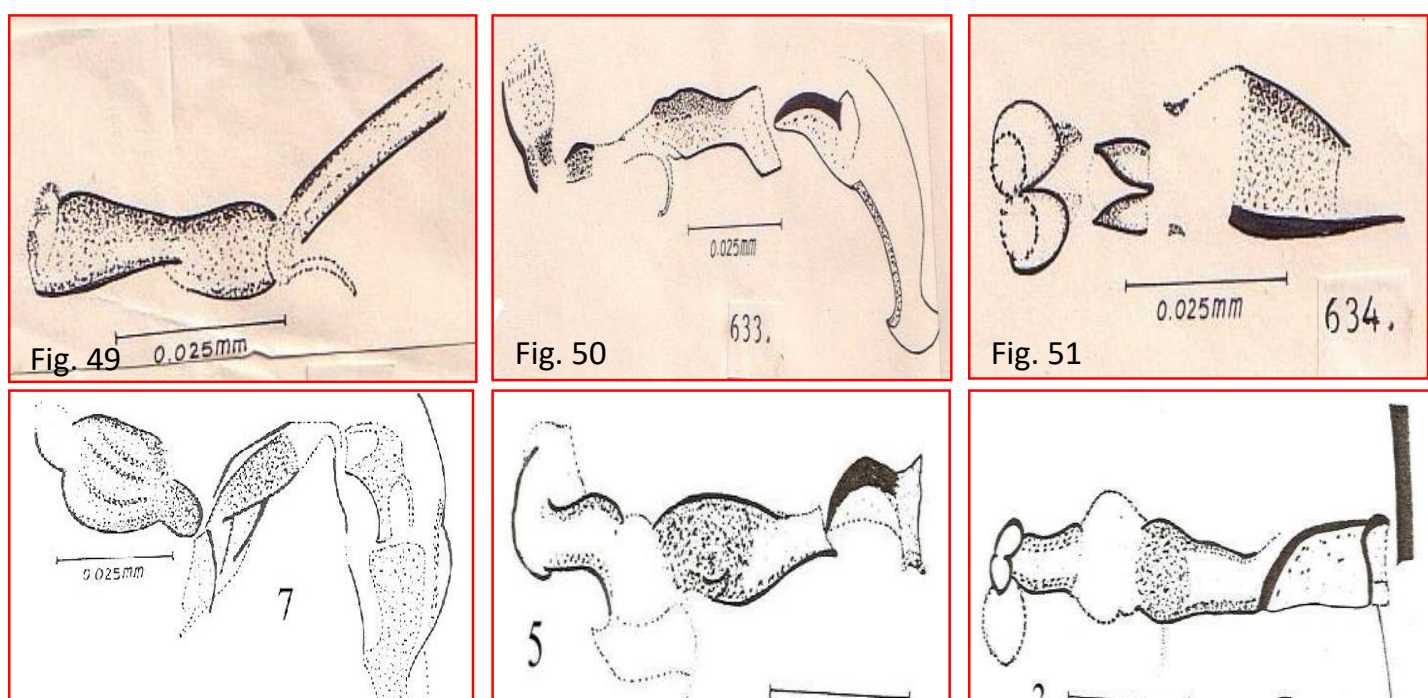

Fig. 52
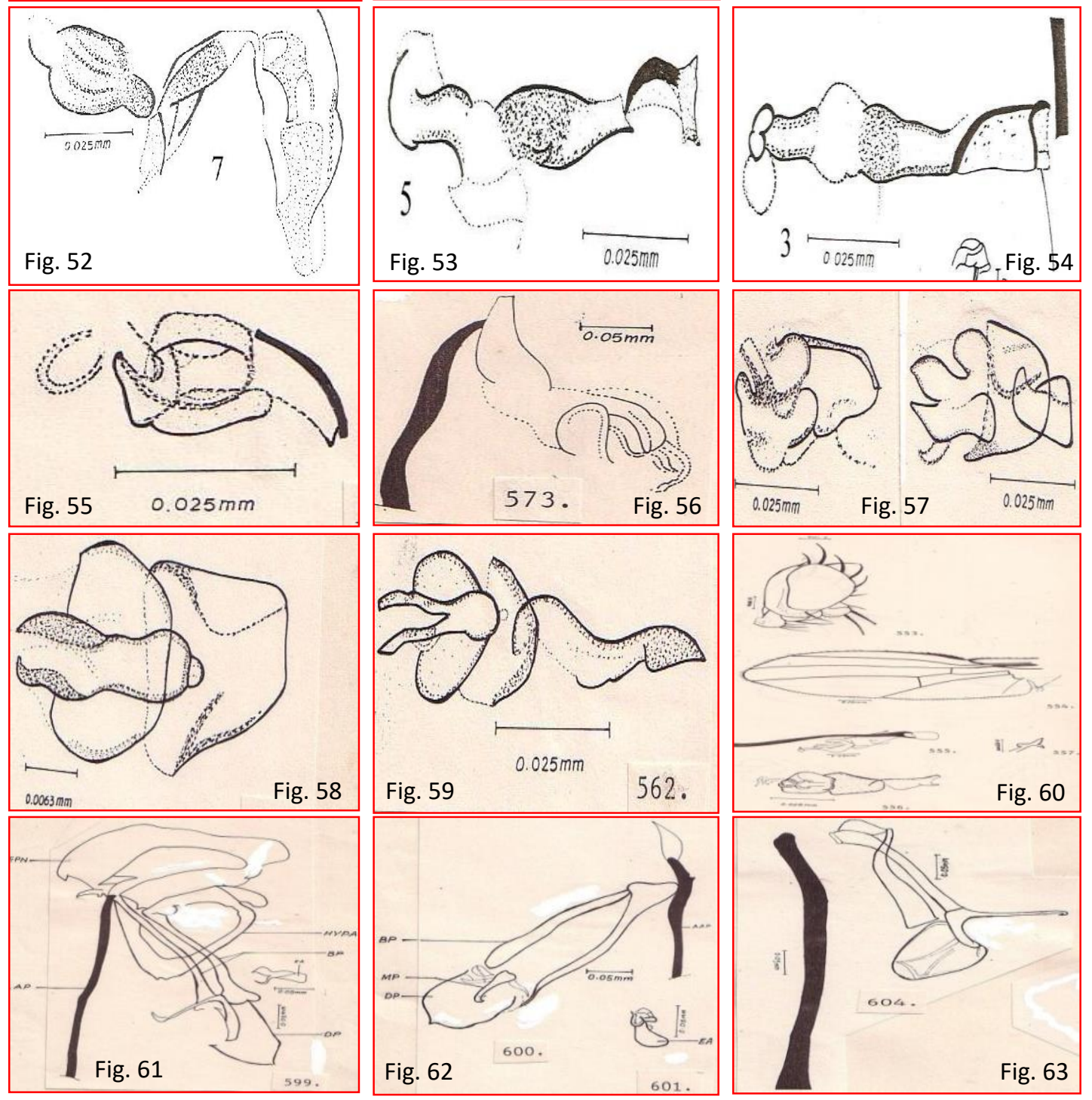


\section{Conclusion}

Interspecific variations in genitalia armature were more than intraspecific variation. Leaf miners were very small flies with very small genitalia armature. Small variations within species might have caused speciation. Present investigation showed that leaf miners kept under one species may actually be an assemblage of more than one species. In present studies major variations found within the species were only considered, based on polytypic species concept. Future studies may look at species complex to categorize more species within each complex.

\section{Acknowledgements}

I express my sincere thanks and indebted to my advisors, Dr. P.K. Pathak and Dr. V.K. Sehgal, Professor, Department of Entomology, College of Agriculture, G.B. Pant University of Agriculture and Technology, Nainital, Uttaranchal, India. I am also highly indebted to University Grants Commision, Government India for providing me Junior and Senior Research fellowship to carry this research at the University. I am also thankful to Department of Zoology, Post- Graduate Campus, Biratnagar and Tribhuvan University, Kathmandu, Nepal for nomination and study leave. My sincere thanks are due to Dr. Gour and his associates, Forest Research Institute, Dehradun for identification of various host plants. I am also thankful to Dr. Y.S. Krishana Associate Professor of Department of Entomology for photographic works. I would like to appreciate for valuable contribution that I received from Dr. Ipe M. Ipe and Dr. Santokh Singh (St. Jones College, Agra, India) on reviewing my work. I am grateful to K.A. Spencer (UK), Prof. G.C.D. Griffiths (Canada), and Prof. Sasakawa M (Japan), for their encouragement to my research. I have honored my advisors, K.A. Spencer and the place Pantnagar by naming new found agromyzid species on these names.

\section{References}

Poudyal, B. 2003. Species determination and some ecological studies of agromyzid flies associated with some commonly cultivated leguminous crops of Jhapa district, Eastern Nepal. M.Sc. thesis. Department of Zoology, Post Graduate Campus, T.U., Biratnagar, Nepal. 87p.

Thapa, M. 2005. Study of field population and diversity of. Leaf miners (Diptera: Agromyaidae) infesting Mung bean Vigna radiata (Linn.) Wilczek grown in Biratnagar eastern Nepal. M.Sc. thesis. Department of Zoology, Post Graduate Campus, T.U., Biratnagar, Nepal. 226p.

Thapa, R.B. 1991. Survey and taxonomic studies on the Agromyzid flies associated with leguminious hosts at Pantnagar in the Northern India. Ph.D. thesis. G.B. Pant University of Agriculture and Technology, Pantnagar. 420p.

Thapa, R.B. 1997. Survey of agromyzid flies (Leaf miners) associated with economically important crops and weed in and around Biratnagar, Eastern, Nepal Final research report of research division, Kirtipur, Tribhuvan University, Department of Zoology, P.G. Campus, Biratnagar. $15 \mathrm{p}$.

Thapa, R.B. 2000. Survey of agromyzid host range in Morang district, Eastern Nepal. Final report of UGC, Research scheme. Department of Biology. Birat Science Campus, Roadcess Chowk, Biratnagar.

Thapa, R.B. 2011. Description of new species of leaf miners (Diptera, Agromyzidae) associated with leguminous host described from northern India. Nepalese Journal of Biosciences 1: 66-82.

Thapa, R.B. 2012. Redescription of Melanagromyza sojae (Zehntner) from India and Nepal. Nepalese Journal of Biosciences 2: 64-70.

Thapa, R.B. 2013. Survey and taxonomic studies on the agromyzid flies (leaf miners) associated with leguminous host plants from India and Nepal. Lap Lambert Academic Publishing, Germany. 126p. http://www.lap-publishing.com 